\title{
Bulk-State Reactions and Improving the Mechanical Properties of Metals through High-Pressure Torsion
}

\author{
Jae-Kyung Han ${ }^{1}$, Jae-il Jang ${ }^{2}$, Terence G. Langdon ${ }^{3}$ and Megumi Kawasaki ${ }^{1, *}$ \\ ${ }^{1}$ School of Mechanical, Industrial and Manufacturing Engineering, Oregon State University, Corvallis, OR 97331, U.S.A. \\ ${ }^{2}$ Division of Materials Science and Engineering, Hanyang University, Seoul 04763, Republic of Korea \\ ${ }^{3}$ Materials Research Group, Department of Mechanical Engineering, University of Southampton, Southampton SO17 1BJ, U.K.
}

\begin{abstract}
This report presents an overview of recent studies demonstrating a bulk-state reaction involving mechanical bonding through the application of high-pressure torsion (HPT) processing on two dissimilar engineering metals. This processing approach was developed by revising the sample set-up and applying the simple procedure of alternately stacking two different metal disks using several different metal combinations. Thus, this report describes the development in microstructure after the bulk-state reactions and the mechanical properties of the HPT-induced Al-Mg, Al-Cu, Al-Fe and Al-Ti alloy systems. A microstructural evaluation confirmed the capability of the HPT procedure for the formation of heterostructures across the disk diameters in these processed alloy systems. Tribology tests and hardness values together with density measurements demonstrated an improved wear resistance and an exceptional specific strength in these alloy systems. The bulk-state reaction by HPT demonstrates a considerable potential for the bonding of dissimilar metals and the fabrication of unique metal systems. [doi:10.2320/matertrans.MF201908]
\end{abstract}

(Received January 25, 2019; Accepted February 28, 2019; Published May 31, 2019)

Keywords: bulk-state reaction, diffusion bonding, high-pressure torsion, intermetallic compound, severe plastic deformation

\section{Introduction}

An advancement in mechanical properties is always needed in engineering metallic materials in order to satisfy the functions and the operation conditions of components or structure for new and advanced industrial applications. Among metallic materials, a number of non-ferrous metals and alloys demonstrate high specific strength in comparison with ferrous metals due to their light-weight densities and these have been widely applied for structural applications in the automotive, aerospace and electronic industries. ${ }^{1,2}$ Nevertheless, further improvements in these materials are indispensable when considering the increased consumption and expanded applications of these alloys.

The processing of bulk nanostructured materials through the application of severe plastic deformation (SPD) ${ }^{3-5)}$ has been well-recognized in the last two decades for advancing the properties and functionalities by the arrangement and control of grain boundaries in a wide range of engineering metals. Among the reported SPD techniques, one of the most effective procedures for grain refinement refers to processing by high-pressure torsion $(\mathrm{HPT})^{6)}$ where a metal disk is subjected to severe torsional straining under a very high compressive pressure: a comprehensive history of the HPT processing technique is available elsewhere. ${ }^{7)}$ In practice, it is found that exceptional microstructural refinement through HPT is available by comparison with other SPD procedures. ${ }^{8)}$ Moreover, the processing technique permits the introduction of significant amounts of point and line defects promoting fast atomic mobility even at ambient temperature. ${ }^{9)}$ Accordingly, numerous demonstrations are currently reported for the use of HPT in the bonding of machining chips ${ }^{10-12)}$ and the consolidation of metallic powders. ${ }^{13-22)}$

Considering these benefits of HPT processing, a new approach of a bulk-state reaction was studied recently which

*Corresponding author, E-mail: megumi.kawasaki@ oregonstate.edu utilizes conventional HPT processing for the synthesis of hybrid nanostructured metallic materials. ${ }^{23-31)}$ Specifically, this approach was applied for light-weight metals and alloys to extend their upper limits of mechanical properties, such as strength and ductility, while maintaining constant or further lowering the alloy density during microstructural refinement and the concurrent solid-state reaction during HPT. Accordingly, this paper was prepared to provide an overview of the procedures of the reported bulk-state reactions by HPT and the consequent detailed developments in microstructure and mechanical properties of the synthesized alloy systems.

\section{Unique Sample Set-Up for a Bulk-State Reaction by HPT}

There are several unique sample set-ups for inducing bulkstate reactions by utilizing a conventional HPT technique in a quasi-constrained setting. ${ }^{32,33)}$ The first report was demonstrated on separate $\mathrm{Al}$ and $\mathrm{Cu}$ metals as shown in Fig. 1(a) where the materials, in a semi-circle shape, were placed on the anvil and processed concurrently by HPT under $6.0 \mathrm{GPa}$ for up to 100 turns: the appearances of the disk sample before and after processing are shown in Fig. 1(b). ${ }^{23)}$ It was demonstrated that the microstructure after HPT involved a combination of nano-scale $\mathrm{Al}$ - and $\mathrm{Cu}$-rich phases as well as two intermetallic phases of $\mathrm{Al}_{2} \mathrm{Cu}$ and $\mathrm{Al}_{4} \mathrm{Cu}_{9}$. A similar concept of the processing procedure was developed for architecturing a spiral microstructure by HPT. This process is depicted in Fig. 2 where (a) the schematic and (b) the actual sample set-up are shown by applying four quartercircle disks of Al6061 alloy and $\mathrm{Cu}$ which were placed on the lower anvil and processed at $2.5 \mathrm{GPa}$ for 1 turn. ${ }^{24)}$ These samples are expected to show the spiral hybrid texture as shown in Fig. 2(c) and (d).

Based on these early studies, a simpler approach for introducing a multi-layered microstructural formation was 

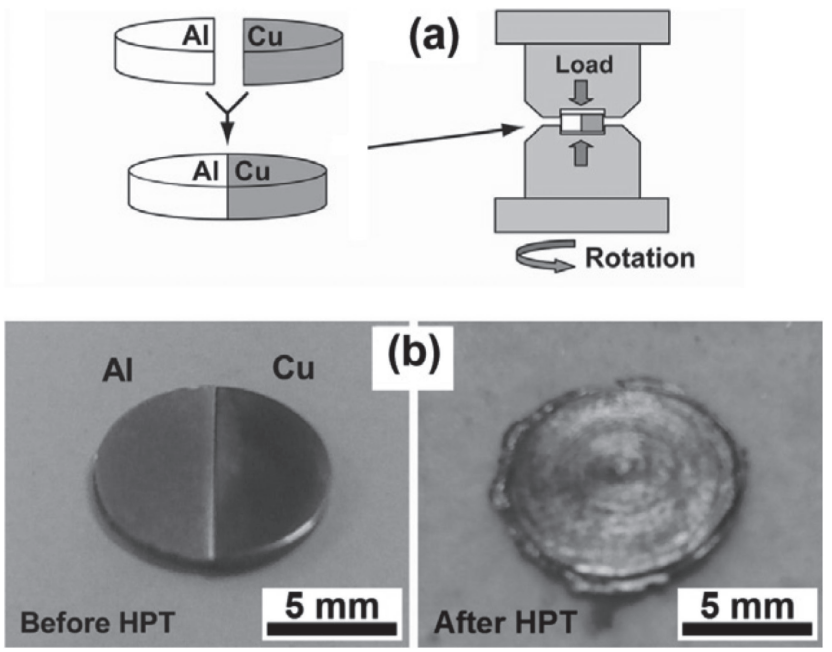

Fig. 1 (a) Schematic illustration of HPT processing and (b) appearance of Al-Cu sample before HPT and after HPT for 100 turns. ${ }^{23)}$

demonstrated by the direct bonding of separate $\mathrm{Al}$ and $\mathrm{Mg}$ disks which were stacked alternately in the order of $\mathrm{Al} /$ $\mathrm{Mg} / \mathrm{Al}$ as shown in Fig. $3^{25)}$ and processed by HPT for up to 5-10 turns ${ }^{25-27)}$ and up to 20 turns $^{28)}$ under $6.0 \mathrm{GPa}$. Specifically, these reports demonstrated a unique nanostructural formation which ultimately led to metal matrix nanocomposites (MMNCs) by introducing a few different types of nano-scale intermetallic compounds. Enhanced mechanical properties and functionality were demonstrated by the extended strength and plasticity ${ }^{25,27,28)}$ of the Al-Mg system and these developments were anticipated by the fast atomic diffusivity of $\mathrm{Mg}$ which was attributed to the high pressure atmosphere in the $\mathrm{Al}$ matrix during HPT. ${ }^{26}$ ) This HPT processing procedure was further applied for several different metal systems including $\mathrm{Al}-\mathrm{Cu},{ }^{29)} \mathrm{Al}-\mathrm{Ti}$ and $\mathrm{Al}-$ $\mathrm{Fe}^{30)}$ and $\mathrm{Mg}-\mathrm{Zn} .{ }^{31)}$ It should be noted that the stacking order of the dissimilar alloy disks for the HPT processing follows the successful cladding of $\mathrm{Al}$ and $\mathrm{Cu}$ plates that was presented earlier by the accumulative roll bonding process

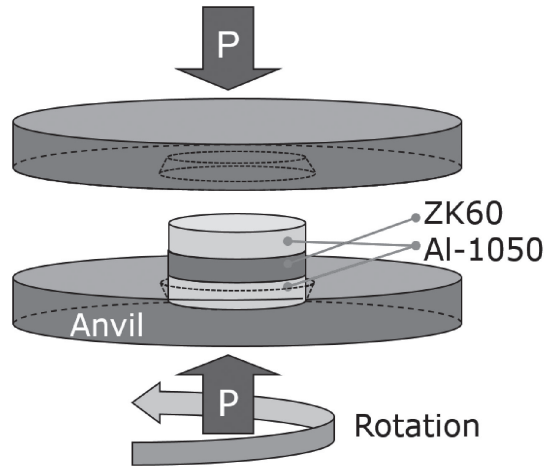

Fig. 3 Schematic illustration of the sample set-up for HPT processing. ${ }^{25)}$

in which a hard phase of $\mathrm{Cu}$ was placed between the soft phase of $\mathrm{Al}{ }^{34)}$

A consistent concept of the mechanical bonding of two dissimilar metals by HPT is used for producing a bi-layered structure of an $\mathrm{Al}-\mathrm{Mg}$ system by using two disks of $\mathrm{Al}$ and $\mathrm{Mg}$ under $6.0 \mathrm{GPa}$ for up to 20 turns $^{35)}$ and for bonding alternately stacked $19 \mathrm{Cu}$ and $18 \mathrm{Ta}$ thin foils to produce a bulk solid under $4.0 \mathrm{GPa}$ for up to 150 turns. $^{36}$ ) Moreover, different types of quasi-constrained HPT was applied for the three-disk procedure on steel and vanadium under $6.0 \mathrm{GPa}$ for 5 turns. $^{37,38)}$ These numerous examples indicate the feasibility and the effectiveness of the unique HPT procedure for synthesizing hybrid alloy structures and ultimately MMNCs. It should be noted that the mechanical bonding by the noted bulk-state reactions by the application of HPT involves the processing of bulk metal disks and it should be differentiated from the mechanical alloying approach by using HPT for powder consolidation and mixing. ${ }^{13-20,22)}$

\section{Bulk-State Reactions by HPT}

\subsection{Mechanical bonding of bulk metals}

In this section, the mechanical bonding introducing severe phase mixtures is described by examining the Al-Fe and Al- (a)

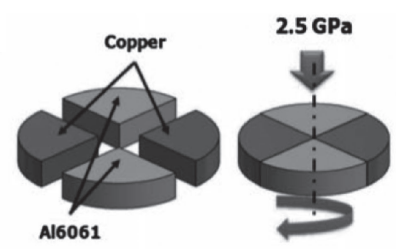

(b)

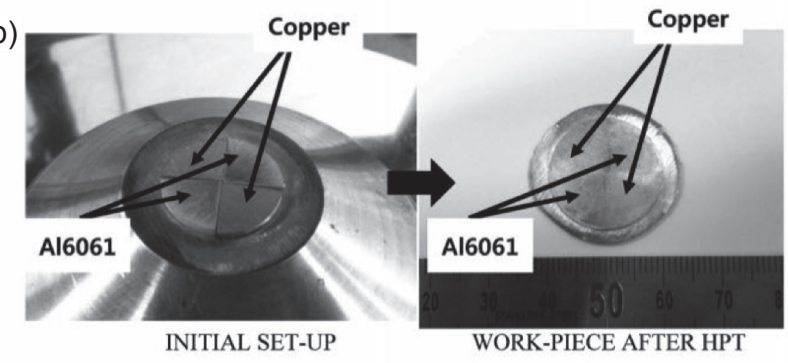

(c)

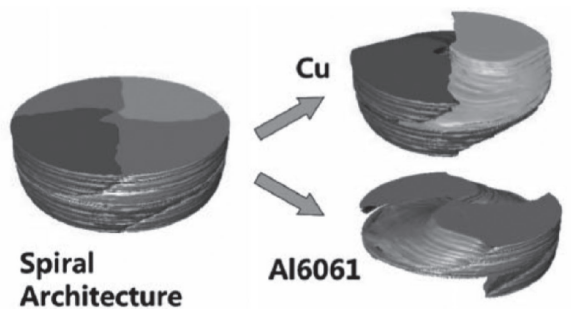

(d)

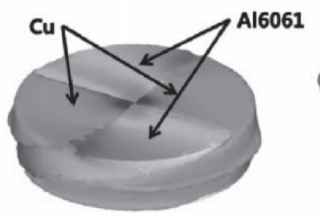

Fig. 2 (a) Four-piece HPT for Cu-Al6061 specimen (schematic). (b) Initial four-piece Cu-Al6061 specimen prior to HPT test (left) and after a full turn of HPT anvil. (c) Reconstructed 3D image of the HPT-processed four-piece Cu-Al6061 specimen after a full turn of HPT anvil. (d) Distribution of the equivalent von Mises stress after a half-turn of HPT anvil. ${ }^{24)}$ 

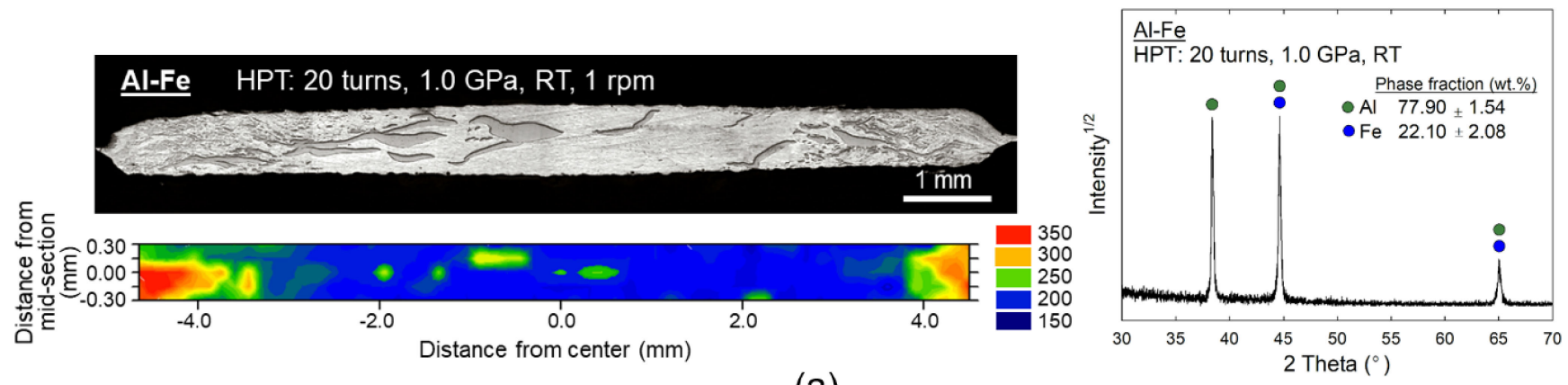

(a)

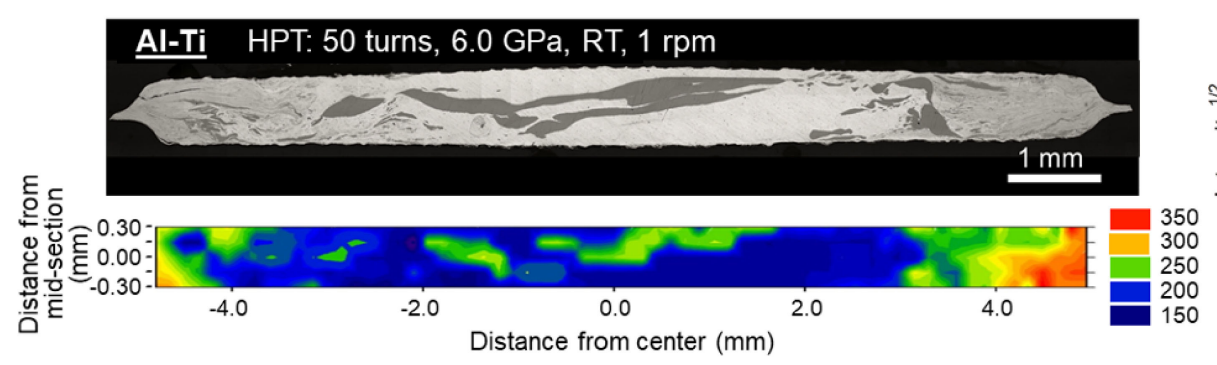

(b)

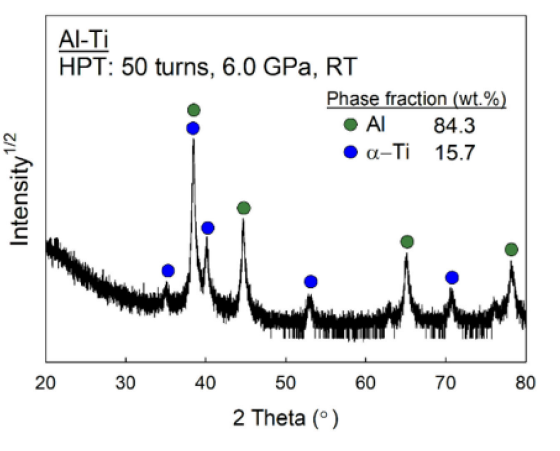

Fig. 4 (Left) overviews of the processed disk microstructure and (right) the XRD profiles for (a) Al-Fe system for 20 turns at 1.0 GPa and (b) Al-Ti system after 50 turns at $6.0 \mathrm{GPa}$, respectively. ${ }^{30}$

Ti systems. ${ }^{30)} \mathrm{A}$ set of $\mathrm{Al}$ and $\mathrm{Fe}$ disks were stacked on the lower anvil in the order of $\mathrm{Al} / \mathrm{Fe} / \mathrm{Al}$ and these were compressed at $6.0 \mathrm{GPa}$ and torsion stressed concurrently for 20 turns at room temperature. Figure 4(a) shows a micrograph taken at the vertical cross-section and a color-coded hardness contour map measured at a consistent location (left) and an X-ray profile taken on the mid-section of the disk surface after 20 HPT turns (right). ${ }^{30)}$ There is a darker phase of $\mathrm{Fe}$ in the brighter matrix of an Al-rich phase and these phases are well bonded without any segregation during the HPT process at room temperature. In practice, the Fe-rich phase at the center until $r<3.0 \mathrm{~mm}$ remained in a large layer where $r$ is the distance from the disk center in which the phase became finer and distributed homogeneously at the disk peripheries at $r>3.0 \mathrm{~mm}$, so that there was the formation of a gradient-type microstructure with radial symmetry in the Al-Fe system after HPT for 20 turns.

The hardness map for the Al-Fe alloy after 20 HPT turns shows very high hardness of $\mathrm{Hv} \approx 350$ at limited regions in the disk periphery at $r>4.0 \mathrm{~mm}$ whereas the central region at $r<4.0 \mathrm{~mm}$ shows a low hardness of $\mathrm{Hv}<150$. These different hardness values and distributions may result in a homogeneously-dispersed ultrafine-grained Fe-rich phase within the disk edge but not in the central region. This is supported by an earlier study on a pure Fe disk processed by HPT for more than 4 turns at $6.0 \mathrm{GPa}$ which introduced a saturated hardness of $\mathrm{Hv}>300$ while the low hardness of $<130$ was observed where staining by torsion was close to zero. ${ }^{39)}$ The X-ray diffraction (XRD) profile shown in Fig. 4(a) for the HPT-processed Al-Fe system describes the presence of only $\mathrm{Al}$ and $\mathrm{Fe}$ phases over the entire mid-surface plane after HPT for 20 turns.

A set of three disks with a Ti disk between two Al disks was processed by the consistent HPT procedure for 50 turns under $6.0 \mathrm{GPa}$ at room temperature. Figure 4(b) shows the optical micrograph and a color-coded hardness contour map taken at the identical location of the vertical cross-section (left) and an X-ray profile taken on the mid-section of the disk surface after 50 HPT turns (right) for the processed AlTi alloy. ${ }^{30)}$ In the micrograph, the darker phase represents a Ti-rich phase and the brighter phase represents the Al matrix.

The HPT-processed Al-Ti shows a very similar micrograph with the result demonstrated for the Al-Fe system in Fig. 4(a). In practice, a radially-symmetrical distribution of the large and fine Ti-rich phase is shown from the disk center towards the periphery with a border at $r \approx 4.0 \mathrm{~mm}$ and it may reflect hardness variations where the high hardness value of $\mathrm{Hv}>350$ is recorded while the hardness at the disk center shows much lower values. For comparison purposes, an earlier report showed that a commercially pure $\mathrm{Ti}$ demonstrated an upper limit of hardness of $\sim 350$ after 4 turns by HPT at $6.0 \mathrm{GPa}$ whereas the hardness without HPT was $\sim 150-180 .^{39)}$ The XRD result proves that only two phases of $\mathrm{Al}$ and $\mathrm{Ti}$ are present in the mid-sectional plane of the alloy system.

It should be noted that an earlier study demonstrated a mechanical alloying approach by the consolidation of $\mathrm{Al}$ and Ti powders through HPT under $6.0 \mathrm{GPa}$ for 50 turns where the conditions of HPT processing is consistent with the bulkstate reaction on the $\mathrm{Al}$ and Ti disks shown in Fig. 4(b). In contrast to the bulk-state reaction, the powder mixture and consolidations by HPT introduced a TiAl intermetallic compound within the Ti-rich and Al-rich phases. ${ }^{40)}$ Therefore, the bulk-state reaction using the whole metal disks and the powder metallurgy technique are two very different procedures and this should be recognized. Nevertheless, these examples of bulk-state reactions by the HPT processing demonstrated a severe mixture and direct bonding of bulk 


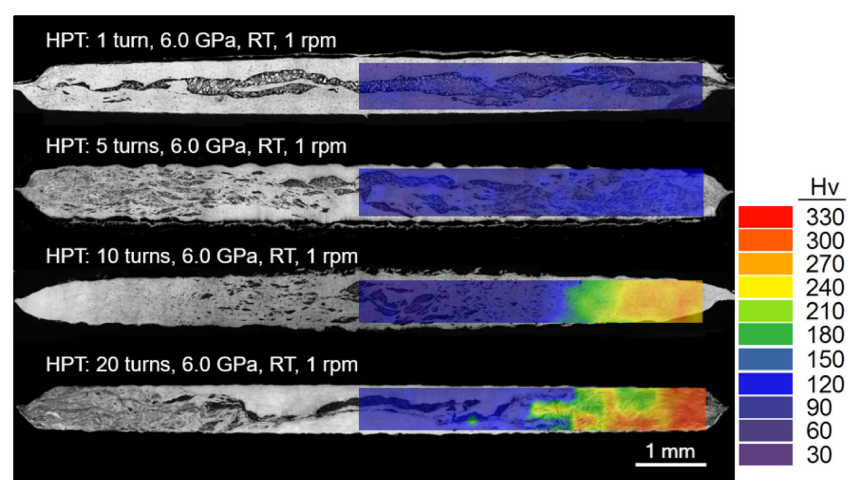

Fig. 5 Optical micrographs for the disks of the Al-Mg alloy system after HPT for, from the top, 1, 5, 10, 20 turns, respectively. ${ }^{25-28)}$ The colorcoded hardness contour maps ${ }^{25,28)}$ are overlapped with the right half of each OM micrograph. ${ }^{30}$ )

metals under the processing conditions and it is a promising manufacturing technique for the mechanical bonding of dissimilar metals and alloys.

\subsection{Synthesis of metal matrix nanocomposites}

Depending on the materials selection, the consistent procedure by HPT for the bulk-state reaction permits the synthesis of intermetallic-reinforced MMNCs. Two examples including $\mathrm{Al}-\mathrm{Mg}$ and $\mathrm{Al}-\mathrm{Cu}$ systems are described in this section.

Separate disks of a commercial purity (CP) aluminum, Al1050 , and a magnesium alloy, ZK60, were processed in the order of $\mathrm{Al} / \mathrm{Mg} / \mathrm{Al}$ by the consistent procedure of HPT as explained earlier under $6.0 \mathrm{GPa}$ for $1,5,10$ and 20 turns. $^{25-28)}$ The cross-sectional overview of these processed disks is shown in Fig. $5^{30}$ ) where, considering a reasonable radial symmetry of microstructure and the hardness development during HPT, ${ }^{41)}$ the color-coded contour hardness maps are overlapped on the right side of the disk surfaces. In the micrographs, the dark phase represents a Mg-rich phase and a bright color represents an Al-rich phase while the darker grey phases at higher numbers of HPT turns show a severe phase mixture requiring more detailed analysis.

After 1 turn by HPT, a Mg-rich disk was well-bonded with the Al disks after 1 turn with necking of the phases but without any visible segregation. At the disk centers, similar microstructural changes as demonstrated in the $\mathrm{Al}-\mathrm{Fe}$ and Al-Ti systems in Fig. 4 are shown for up to 20 turns where a large Mg-rich phase remains within $r \approx 2.5 \mathrm{~mm}$. By contrast, the disk peripheries showed an unexpected feature where the finer Mg-rich phases which were visible at the disk edges for up to 5 turns disappeared after 10 to 20 turns. In practice, the disk edges after HPT for 10-20 turns tend to show a single phase-like microstructure with fine flow patterns which appear extensively and demonstrate a darker microstructure especially after $20 \mathrm{HPT}$ turns. Moreover, the peripheral region without any visible $\mathrm{Mg}$-rich phases is widened reasonably to $r>3.0 \mathrm{~mm}$ with higher numbers of HPT turns after 10 to 20 .

The hardness measured at the disk edges at $r \geq 4.0 \mathrm{~mm}$ showed exceptionally high values of $\mathrm{Hv} \approx 270$ and $\sim 330$ after 10 and $20 \mathrm{HPT}$ turns, respectively. For comparison purposes, the base materials of the Al-1050 and the ZK60 alloys exhibited homogeneous hardness distributions with $\mathrm{Hv} \approx 65$ and $\sim 110$, respectively, along the disk diameters after HPT for 5 or more turns. It is also apparent that the high hardness regions at the disk edges expand with increasing HPT turns by 10 to 20 in the Al-Mg system. Therefore, detailed microstructural analysis was conducted at the disk edges after 10 turns $^{25-27)}$ and 20 turns. $^{28)}$

Figure 6 shows a set of a transmission electron microscopy (TEM) micrographs and an XRD profile measured at the disk edges of the Al-Mg system after HPT for (a) and (b) 10 turns $^{25)}$ and (c) and (d) 20 turns, ${ }^{28)}$ respectively. It should be noted that, in a part of the XRD analysis, the disk edges were scanned by carefully removing the central regions at $r \geq 2.0 \mathrm{~mm}$ and the data were quantitatively evaluated by MAUD to acquire the phase fractions of $\mathrm{Al}, \mathrm{Mg}$ and any additional phases, and the result is listed in each XRD profile. The procedure of removing the central region was to eliminate relatively large $\mathrm{Mg}$-rich regions close to the disk centers whereas it is inevitable to remove them completely from the XRD measurement area and some remaining $\mathrm{Mg}$ phase was involved during the analysis.

Both disk edges demonstrated an equiaxed nanostructure with average grain sizes of $d \approx 90 \mathrm{~nm}$ and $\sim 60 \mathrm{~nm}$ after 10 turns and 20 turns, respectively. Moreover, in both disk peripheries, a series of TEM examinations suggested any $\mathrm{Mg}$-rich phase was present after HPT over 10 turns. The XRD results indicate there is evidence of a $\gamma-\mathrm{Al}_{12} \mathrm{Mg}_{17}$ intermetallic compound in the $\mathrm{Al}$ matrix at the disk edges after HPT for 10 and 20 turns. Some additional proof by compositional analysis and further TEM measurements confirmed the presence of the intermetallic phases of the $\gamma-\mathrm{Al}_{12} \mathrm{Mg}_{17}$ as well as an $\alpha-\mathrm{Al}_{3} \mathrm{Mg}_{2}$ phase in the ultrafinegrained matrix, thereby demonstrating synthesis of MMNCs at the disk edges of the Al-Mg system by HPT. The presence of these hard intermetallic phases in the ultrafine-grained matrix phase are anticipated to introduce such exceptional hardness at the disk peripheries as shown in Fig. 5.

Synthesis of an MMNC through the HPT technique was demonstrated recently on an $\mathrm{Al}-\mathrm{Cu}^{29)}$ system by applying a consistent sample set-up using the $\mathrm{Al}$ and $\mathrm{Cu}$ disks in the order of $\mathrm{Al} / \mathrm{Cu} / \mathrm{Al}$. In practice, the $\mathrm{Al}-\mathrm{Cu}$ system processed by HPT demonstrated the formation of an MMNC containing three intermetallic phases of $\mathrm{Al}_{2} \mathrm{Cu}, \mathrm{AlCu}$ and $\mathrm{Al}_{4} \mathrm{Cu}_{9}$ within the equiaxed ultrafine matrix having an average grain size of $\sim 30 \mathrm{~nm}$ after 60 turns under $6.0 \mathrm{GPa}$. As was demonstrated in the $\mathrm{Al}-\mathrm{Mg}$ system, a consistent trend of high hardness at the disk peripheries was demonstrated at wider peripheries with increasing numbers of HPT turns from 20 to 60 turns with a significantly high hardness of $\mathrm{Hv} \approx 500$ in the $\mathrm{Al}-\mathrm{Cu}$ system after 60 turns. In conclusion, these reported results demonstrate there is a considerable potential for utilizing HPT processing for the mechanical bonding of dissimilar metals as a manufacturing technique and for the development of new alloy systems and ultimately for the formation of MMNCs.

\section{Tribological and Mechanical Properties}

The microstructure formed through the mechanical bonding by HPT often contains a gradient-type microstructure 


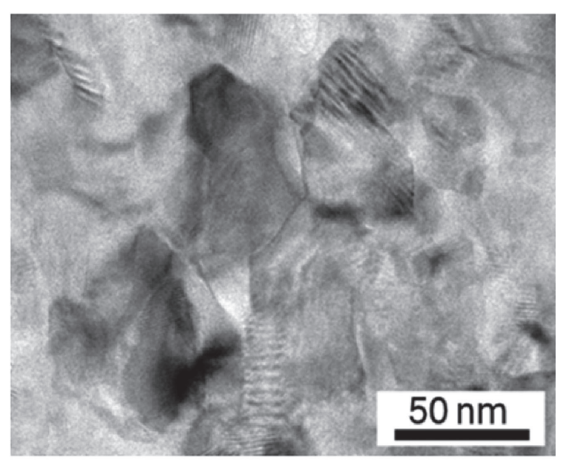

(a)

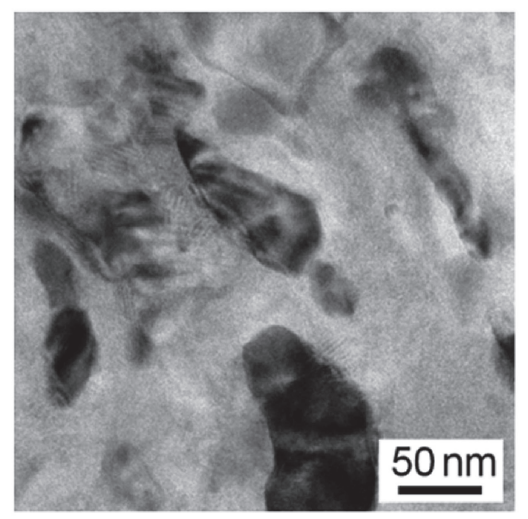

(c)

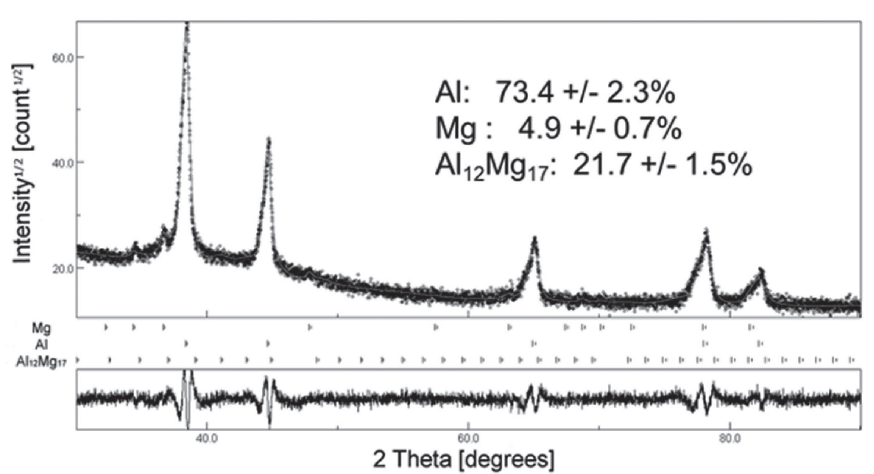

(b)

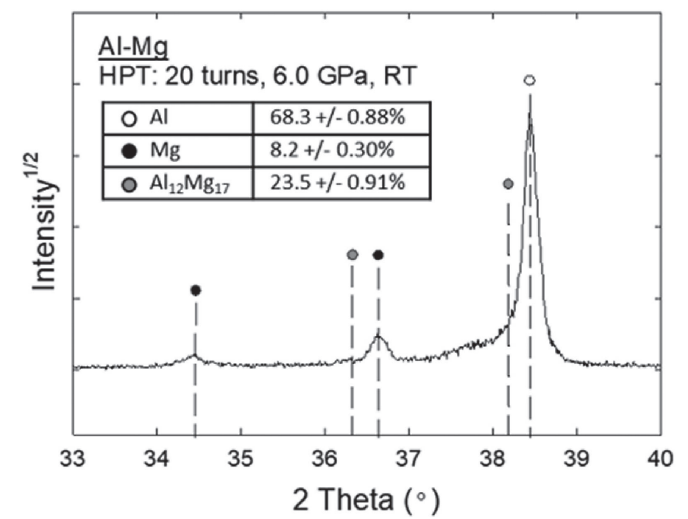

(d)

Fig. 6 TEM bright-field images and the XRD profiles with the MAUD estimations taken at the Al-Mg disk edges after HPT for (a) and (b) 10 turns $^{25)}$ and (c) and (d) 20 turns $^{28)}$ by HPT.

or a heterogeneous structure ${ }^{42-46)}$ in terms of grain sizes and compositions as seen in the radial direction from the centers of the HPT-processed disks. These heterostructured materials demonstrate a high potential for exhibiting excellent mechanical properties and functionalities. ${ }^{47)}$ Thus, this section describes two selected properties of tribological effects and specific strength of the mechanically-bonded Al-Fe system and of the MMNCs in the $\mathrm{Al}-\mathrm{Mg}$ and $\mathrm{Al}-\mathrm{Cu}$ systems.

Small-scale sliding tests were conducted to evaluate the morphology or the wear scar, and thus to determine the type of wear behavior, under a load of $10.0 \mathrm{~N}$ and a sliding stroke of $2.0 \mathrm{~mm}$ at a sliding speed of $0.004 \mathrm{~m} \mathrm{~s}^{-1}$ for a total sliding distance of $20 \mathrm{~m}$ on the surfaces at the disk edges of the $\mathrm{Al}-\mathrm{Fe}$ system after 20 turns of HPT as shown in Fig. 4(a). The results are shown in Fig. 7 where (a) provides a threedimensional depth-sensing photo at a vertical section in the middle of the wear track with a color key denoting the detailed depth information, (b) shows an SEM micrograph of the worn surface and (c) shows the optical micrograph magnifying the vertical worn section of the Al-Fe system after HPT for 20 turns. For both the SEM and optical micrographs in Fig. 7(b) and (c), a darker phase represents an Fe-rich phase and the brighter phase represents an Al-rich phase. It is evident from the depth-sensing photo in Fig. 7(a) that there is a consistent width of $<60 \mu \mathrm{m}$ and a depth of $<4.0 \mu \mathrm{m}$ at the middle of the worn trace. The SEM photo in Fig. 7(b) capturing the end of the sliding track shows the stacked wear debris, thereby demonstrating an adhesive wear behavior in the HPT-processed Al-Fe system where this type of wear mechanism is generally observed in ductile metals and alloys.

A promising wear characteristic can be seen in the Al-Fe system processed by HPT. At the disk edge of the HPTprocessed metals after high numbers of HPT turns, homogeneous distributions of the $\mathrm{Al}$ and $\mathrm{Fe}$ phases were visible in Fig. 4(a). It is apparent at the vertical section of the worn surface in Fig. 7(c) that the widely distributed hard Fe-rich phases are located over the worn surface. Thus, the additional volume loss by wear was prevented by the presence of the hard $\mathrm{Fe}$ phases after the soft $\mathrm{Al}$ phases above the $\mathrm{Fe}$ phase were taken during wear testing. This result suggests an excellent potential for making use of the HPT processing for mechanical bonding of dissimilar metals having different hardness to improve the wear resistance in addition to increasing the hardness of the processed metal systems.

Small-scale sliding tests were also conducted on the disk edges forming MMNCs in the Al-Cu system after HPT for 20 and 60 turns at $6.0 \mathrm{GPa}^{29)}$ The testing used loads of 10 $60 \mathrm{~N}$ and a sliding distance of $2.0 \mathrm{~mm}$ at a speed of $0.002 \mathrm{~m} \mathrm{~s}^{-1}$ for a total sliding distance of $100 \mathrm{~m}$ on the Al$\mathrm{Cu}$ disk peripheral surfaces. Evaluating the wear properties within the consistent metal system, it is reasonable to compute the wear rate, $w_{R}$, by measuring the wear volume (or volume loss), $V$, and applying the sliding distance, $L$, in the following form:

$$
w_{R}=\frac{V}{L}=\frac{w}{L \rho}
$$




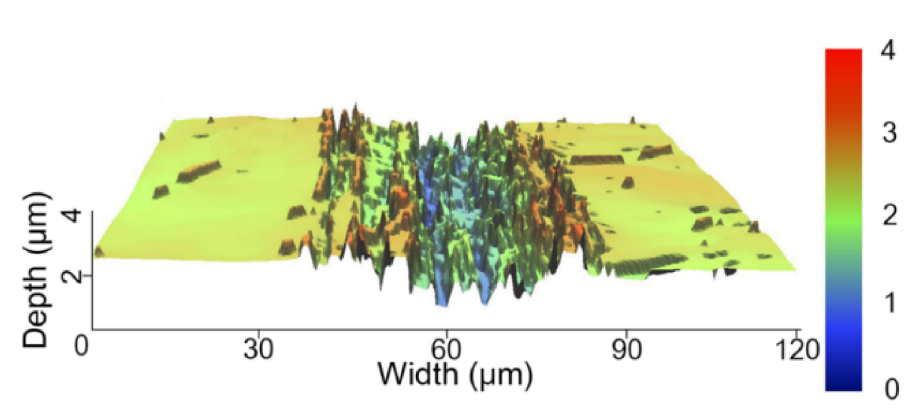

(a)

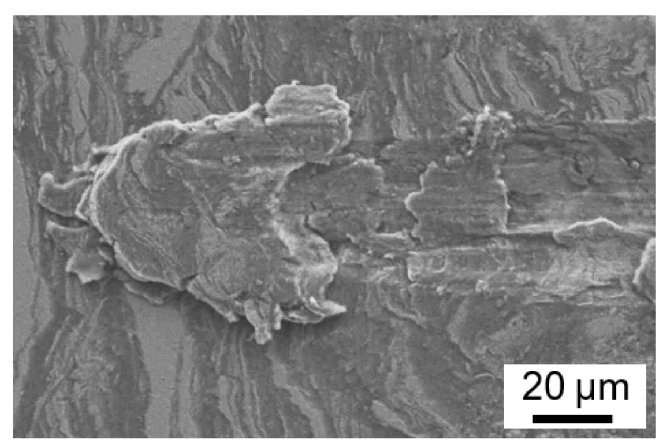

(b)

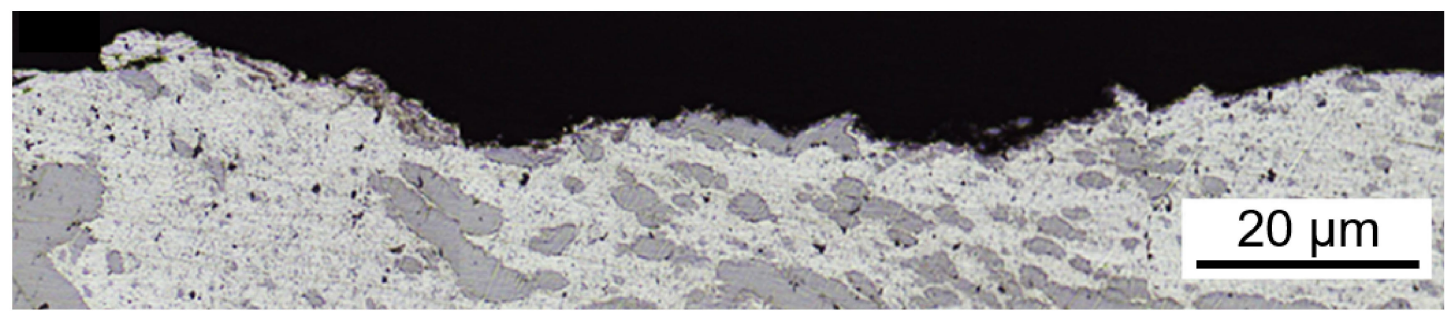

(c)

Fig. 7 (a) A three-dimensional depth-sensing photo showing a vertical section in the middle of the wear track, (b) an SEM micrograph of the wear surface from the top and (c) an optical micrograph magnifying the vertical section of the wear track for the Al-Fe system after HPT for 20 turns.

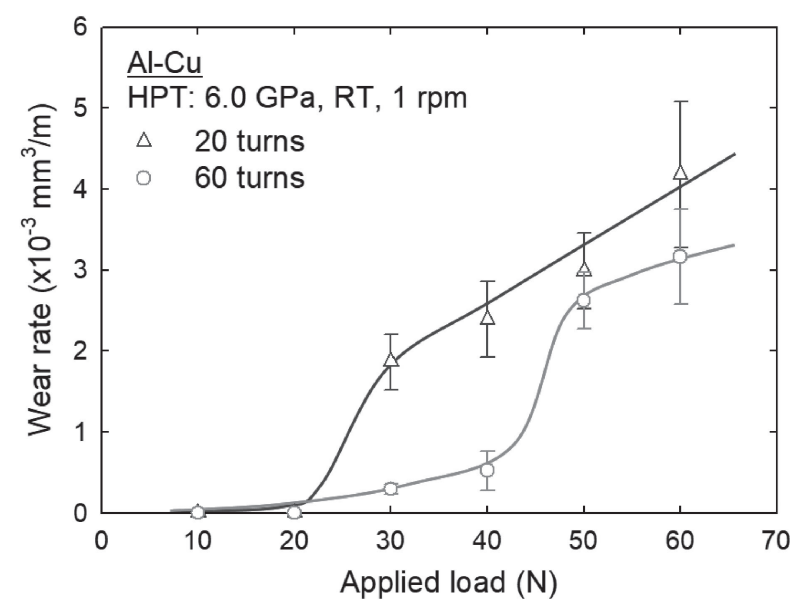

Fig. 8 The change in wear rate with increasing applied load for the $\mathrm{Al}-\mathrm{Cu}$ system after 20 and 60 HPT turns. ${ }^{29)}$

where $W$ is the weight loss and $\rho$ is the density of the material. Figure 8 describes the changes in the wear rate with increasing applied loads for the Al-Cu system processed through 20 and 60 HPT turns where the densities of the disk edges were carefully measured as 4.466 and $4.321 \mathrm{~g} \mathrm{~cm}^{-3}$ for the samples after 20 and $60 \mathrm{HPT}$ turns. ${ }^{29)}$ There is a large increase in the wear rate accelerating the wear of the Al-Cu system at $20-30 \mathrm{~N}$ after $20 \mathrm{HPT}$ turns and this increase shifts to $45-50 \mathrm{~N}$ after HPT for 60 turns. Thus, this behavior confirms a significant improvement in wear resistance by extending the range of the applied load and lowering the wear rate in the $\mathrm{Al}-\mathrm{Cu}$ system with increasing HPT turns.

In order to compare the wear properties in different materials, it is reasonable to estimate the specific wear rate, $k$, from Archard's equation: ${ }^{48)}$

$$
k=\frac{V}{P L}=\frac{W}{P L \rho}
$$

where $P$ is the applied normal load. Accordingly, the specific wear rates are calculated and summarized for the alloys introduced by the bulk-state reaction through the HPT processing of the $\mathrm{Al}-\mathrm{Mg}, \mathrm{Al}-\mathrm{Cu}$ and $\mathrm{Al}-\mathrm{Fe}$ systems. For comparison purposes, the evaluations were processed including the initial materials of $\mathrm{CP} \mathrm{Al}, \mathrm{Cu}, \mathrm{Fe}$ and the $\mathrm{ZK}$ $60 \mathrm{Mg}$ alloys after HPT for 10 turns. Specifically, the smallscratch tests with a $2.0 \mathrm{~mm}$ stroke were conducted under a load of $3.0 \mathrm{~N}$ for a total distance of $20 \mathrm{~m}$ for the $\mathrm{Al}-\mathrm{Mg}^{28)}$ and $\mathrm{Al}-\mathrm{Fe}^{30)}$ systems after $\mathrm{HPT}$ as well as $\mathrm{CP} \mathrm{Al}, \mathrm{Mg}$ and $\mathrm{Cu}$, and under $30 \mathrm{~N}$ for a total distance of $100 \mathrm{~m}$ for the $\mathrm{Al}-\mathrm{Cu}$ alloy $^{29)}$ and for a total distance of $50 \mathrm{~m}$ for the $\mathrm{CP} \mathrm{Cu}$.

The second to the fifth columns in Table 1 show a summary of the carefully measured density at the disk edges after HPT and the volume loss after the wear tests, and estimated volume loss and the specific wear rate for the Al$\mathrm{Mg}, \mathrm{Al}-\mathrm{Cu}$ and $\mathrm{Al}-\mathrm{Fe}$ systems after the mechanical bonding by HPT and the initial materials of $\mathrm{Al}, \mathrm{Cu}, \mathrm{Mg}$, and $\mathrm{Fe}$ alloys. There are two important points in the wear results. Firstly, it is apparent that the density of the alloys after the mechanical bonding by HPT takes values between the two density values of the corresponding initial metals, thereby demonstrating the light-weight of the engineering metals when these are simply bonded by HPT. Secondly, comparisons of the specific wear rates provide a consistent demonstration of significantly reduced specific wear rates, thereby developing the wear resistance in all mechanically-bonded $\mathrm{Al}-\mathrm{Mg}, \mathrm{Al}-\mathrm{Cu}$ and $\mathrm{Al}-\mathrm{Fe}$ systems by comparison with the initial metals processed by HPT.

From the measured density and hardness values which can be computed to the equivalent yield strength, an additional essential property of specific strength is estimated for the 
Table 1 (Second to fifth columns) the measured density after HPT, weight loss, wear volume and the estimated specific wear rate and (sixth and seventh columns) the maximum Vickers hardness value and the estimated specific strength for the disk edges of the Al-Mg, ${ }^{28}$ $\mathrm{Al}-\mathrm{Cu}^{29)}$ and $\mathrm{Al}-\mathrm{Fe}$ systems after HPT and for the base metals of $\mathrm{CP} \mathrm{Al},{ }^{28)} \mathrm{ZK} 60,{ }^{28)} \mathrm{CP} \mathrm{Cu}^{29)}$ and $\mathrm{CP} \mathrm{Fe}$ after $10 \mathrm{HPT}$ turns, respectively.

\begin{tabular}{|c|c|c|c|c|c|c|}
\hline \multirow{2}{*}{ Material } & \multicolumn{3}{|l|}{ Wear property } & \multicolumn{2}{l|}{ Specific strength } \\
\cline { 2 - 7 } & $\begin{array}{c}\text { Density } \\
\left(\mathrm{g} \mathrm{cm}^{-3}\right)\end{array}$ & $\begin{array}{c}\text { Weight } \\
\text { loss } \\
(\mathrm{g})\end{array}$ & $\begin{array}{c}\text { Wear } \\
\text { volume } \\
\left(\mathrm{mm}^{3}\right)\end{array}$ & $\begin{array}{c}\text { Specific wear } \\
\text { rate }\left(\times 10^{-3}\right. \\
\left.\mathrm{mm}^{3} \mathrm{~N}^{-1} \mathrm{~m}^{-1}\right)\end{array}$ & $\begin{array}{c}\text { Maximum } \\
\text { hardness } \\
(\mathrm{Hv})\end{array}$ & $\begin{array}{c}\text { Specific } \\
\text { strength } \\
\left(\mathrm{MPa} \mathrm{cm}^{3} \mathrm{~g}^{-1}\right)\end{array}$ \\
\hline Al-Mg (HPT: 20 turns) ${ }^{28)}$ & 2.34 & 0.00075 & 0.32 & 5 & 330 & 455 \\
\hline Al-Cu (HPT: 60 turns) $)^{29)}$ & 4.32 & 0.00014 & 0.032 & 0.1 & 400 & 300 \\
\hline Al-Fe (HPT: 20 turns) & 3.81 & 0.00010 & 0.027 & 9 & 320 & 296 \\
\hline CP Al (HPT: 10 turns) ${ }^{28)}$ & 2.73 & 0.00230 & 0.84 & 14 & 65 & 80 \\
\hline ZK60 (HPT: 10 turns) $)^{28)}$ & 1.84 & 0.00310 & 1.68 & 28 & 110 & 190 \\
\hline CP Cu (HPT: 10 turns) ${ }^{29)}$ & 8.96 & 0.00806 & 0.90 & 0.6 & 150 & 55 \\
\hline CP Fe (HPT: 10 turns) & 7.87 & 0.00188 & 0.24 & 4 & 310 & 128 \\
\hline
\end{tabular}

HPT-induced $\mathrm{Al}-\mathrm{Mg}, \mathrm{Al}-\mathrm{Cu}$ and $\mathrm{Al}-\mathrm{Fe}$ alloy systems. The summarized Vickers microhardness values and the estimated specific strengths are listed in the last two columns in Table 1 . The summary demonstrates significantly improved hardness values, thereby showing excellent specific strengths of $296 \mathrm{MPa} \mathrm{cm}^{3} \mathrm{~g}^{-1}, 455 \mathrm{MPa} \mathrm{cm}^{3} \mathrm{~g}^{-1}$ and $300 \mathrm{MPa} \mathrm{cm}^{3} \mathrm{~g}^{-1}$, are estimated due to the lowered densities by the severe mixture of the dissimilar metals in the $\mathrm{Al}-\mathrm{Fe}$ system after HPT and by the formation of hard intermetallic phases in the nanostructured matrix in the $\mathrm{Al}-\mathrm{Mg}$ and $\mathrm{Al}-\mathrm{Cu}$ systems, respectively. The specific hardness of these mechanicallybonded metals is significantly higher than the base materials of the $\mathrm{Al}, \mathrm{Mg}$ and $\mathrm{Cu}$, and in fact they are higher than any other structural metals including steels exhibiting $\sim 150$ $\mathrm{MPacm} \mathrm{g}^{-1}$ and the engineering polymeric composites, ceramics and carbon fibers showing $\sim 200 \mathrm{MPa} \mathrm{cm}^{3} \mathrm{~g}^{-1}$.) In summary, therefore, the present report outlines a significant potential for the bulk-state reactions by HPT processing for successfully introducing the mechanical bonding of dissimilar metals and synthesizing lightweight and strong alloy systems using separate conventional metals.

\section{Conclusions}

(1) Bulk-state reactions by the mechanical bonding of engineering metals was successfully demonstrated by utilizing conventional HPT processing on two dissimilar metal disks by introducing $\mathrm{Al}-\mathrm{Fe}, \mathrm{Al}-\mathrm{Ti}, \mathrm{Al}-\mathrm{Mg}$ and $\mathrm{Al}-\mathrm{Cu}$ systems. In practice, the $\mathrm{Al}-\mathrm{Fe}$ and $\mathrm{Al}-\mathrm{Ti}$ systems demonstrated severe mixture of the Al-rich and the corresponding other phases in each system at the disk edges. By contract, the $\mathrm{Al}-\mathrm{Mg}$ and $\mathrm{Al}-\mathrm{Cu}$ systems demonstrated the synthesis of MMNCs by the formation of intermetallic phases at the disk edges after HPT.

(2) Small-scale tribology testing on the Al-Fe system showed an improved wear resistance due to the homogeneously-distributed Fe-rich phases within the Al matrix in the alloy system processed by HPT. All HPT-induced alloy systems demonstrated an excellent wear resistance with a lowering of the specific wear rates by comparison with their corresponding base metals.

(3) Excellent lightweight characteristics with improved hardness confirm the introduction of exceptional specific strength at the disk edges of these alloy systems processed by the solid-state reactions through HPT. The HPT processing demonstrates the feasibility of the introduction of heterostructures in bulk metals leading to variations in mechanical properties and functionalities that may attract future applications for these bulk nanostructured materials. Moreover, there is a considerable potential for applying the solid-state reaction by HPT for the bonding of dissimilar metals as a manufacturing technique and for the development of new alloy systems.

\section{Acknowledgments}

This study was supported in part by the National Science Foundation of the United States under Grant No. DMR1810343 (MK \& JKH), in part by the National Research Foundation of Korea (NRF) grants funded by the Ministry of Science and ICT, No. 2015R1A5A1037627 and No. 2017R1A2B4012255(JIJ) and in part by the European Research Council under ERC Grant Agreement No. 267464SPDMETALS (TGL).

\section{REFERENCES}

1) K. Lu: Science 328 (2010) 319-320.

2) M.T. Pérez Prado and C.M. Cepeda-Jiménez: Nature 528 (2015) 486487.

3) R.Z. Valiev, Y. Estrin, Z. Horita, T.G. Langdon, M.J. Zehetbauer and Y.T. Zhu: JOM 58(4) (2006) 33-39.

4) R.Z. Valiev, Y. Estrin, Z. Horita, T.G. Langdon, M.J. Zehetbauer and Y.T. Zhu: JOM 68 (2016) 1216-1226.

5) R.Z. Valiev, Y. Estrin, Z. Horita, T.G. Langdon, M.J. Zehetbauer and Y.T. Zhu: Mater. Res. Lett. 4 (2016) 1-21.

6) A.P. Zhilyaev and T.G. Langdon: Prog. Mater. Sci. 53 (2008) 893-979.

7) K. Edalati and Z. Horita: Mater. Sci. Eng. A 652 (2016) 325-352.

8) T.G. Langdon: Acta Mater. 61 (2013) 7035-7059. 
9) X. Sauvage, G. Wilde, S.V. Divinski, Z. Horita and R.Z. Valiev: Mater Sci. Eng. A 540 (2012) 1-12.

10) A.P. Zhilyaev, A.A. Gimazov, G.I. Raab and T.G. Langdon: Mater. Sci. Eng. A 486 (2008) 123-126.

11) K. Edalati, Y. Yokoyama and Z. Horita: Mater. Trans. 51 (2010) 23 26.

12) M.M. Castro, P.H.R. Pereira, A. Isaac, R.B. Figueiredo and T.G. Langdon: J. Alloys Compd. 780 (2019) 422-427.

13) A.V. Korznikov, I.M. Safarov, D.V. Laptionok and R.Z. Valiev: Acta Metall. Mater. 39 (1991) 3193-3197.

14) V.V. Stolyarov, Y.T. Zhu, T.C. Lowe, R.K. Islamgaliev and R.Z. Valiev: Mater. Sci. Eng. A 282 (2000) 78-85.

15) X. Sauvage, P. Jessner, F. Vurpillot and R. Pippan: Scr. Mater. 58 (2008) 1125-1128.

16) K. Kaneko, T. Hata, T. Tokunaga and Z. Horita: Mater. Trans. 50 (2009) 76-81.

17) K. Edalati, Z. Horita, H. Fujiwara and K. Ameyama: Metall. Mater Trans. A 41 (2010) 3308-3317.

18) A. Bachmaier, M. Kerber, D. Setman and R. Pippan: Acta Mater. 60 (2012) 860-871.

19) J.M. Cubero-Sesin and Z. Horita: Mater. Sci. Eng. A 558 (2012) 462 471.

20) Y. Zhang, S. Sabbaghianrad, H. Yang, T.D. Topping, T.G. Langdon, E.J. Lavernia, J.M. Schoenung and S.R. Nutt: Metall. Mater. Trans. A 46 (2015) 5877-5886.

21) A.P. Zhilyaev, G. Ringot, Y. Huang, J.M. Cabrera and T.G. Langdon: Mater. Sci. Eng. A 688 (2017) 498-504.

22) Y. Huang, P. Bazarnik, D. Wan, D. Luo, P.H.R. Pereira, M Lewandowska, J. Yao, B.E. Hayden and T.G. Langdon: Acta Mater. 164 (2019) 499-511.

23) K. Oh-ishi, K. Edalati, H.S. Kim, K. Hono and Z. Horita: Acta Mater 61 (2013) 3482-3489.

24) O. Bouaziz, H.S. Kim and Y. Estrin: Adv. Eng. Mater. 15 (2013) 336340

25) B. Ahn, A.P. Zhilyaev, H.-J. Lee, M. Kawasaki and T.G. Langdon: Mater. Sci. Eng. A 635 (2015) 109-117.

26) M. Kawasaki, B. Ahn, H.-J. Lee, A.P. Zhilyaev and T.G. Langdon: J. Mater. Res. 31 (2016) 88-99.

27) B. Ahn, H.-J. Lee, I.-C. Choi, M. Kawasaki, J.-i. Jang and T.G. Langdon: Adv. Eng. Mater. 18 (2016) 1001-1008.
28) J.-K. Han, H.-J. Lee, J.-i. Jang, M. Kawasaki and T.G. Langdon: Mater. Sci. Eng. A 684 (2017) 318-327.

29) J.-K. Han, D.K. Han, G.Y. Liang, J.-i. Jang, T.G. Langdon and M. Kawasaki: Adv. Eng. Mater. 20 (2018) 1800642.

30) M. Kawasaki, J.-K. Han, D.-H. Lee, J.-i. Jang and T.G. Langdon: J. Mater. Res. 33 (2018) 2700-2710.

31) D. Hernández-Escobar, Z.U. Raman, H. Yilmazer, M. Kawasaki and C.J. Boehlert: Philos. Mag. 99 (2019) 557-584.

32) R.B. Figueiredo, P.R. Cetlin and T.G. Langdon: Mater. Sci. Eng. A 528 (2011) 8198-8204

33) R.B. Figueiredo, P.H.R. Pereira, M.T.P. Aguilar, P.R. Cetlin and T.G. Langdon: Acta Mater. 60 (2012) 3190-3198.

34) M. Eizadjou, A. Kazemi Talachi, H. Danesh Manesh, H. Shakur Shahabi and K. Janghorban: Compos. Sci. Technol. 68 (2008) 20032009.

35) X. Qiao, X. Li, X. Zhang, Y. Chen, M. Zheng, I.S. Golovin, N. Gao and M.J. Starink: Mater. Lett. 181 (2016) 187-190.

36) N. Ibrahim, M. Peterlechner, F. Emeis, M. Wegner, S.V. Divinski and G. Wilde: Mater. Sci. Eng. A 685 (2017) 19-30.

37) S.O. Rogachev, R.V. Sundeev and V.M. Khatkevich: Mater. Lett. 173 (2016) 123-126.

38) S.O. Rogachev, S.A. Nikulin, A.B. Rozhnov, V.M. Khatkevich, T.A. Nechaykina, M.V. Gorshenkov and R.V. Sundeev: Metall. Mater. Trans. A 48 (2017) 6091-6101.

39) K. Edalati and Z. Horita: Mater. Trans. 51 (2010) 1051-1054.

40) K. Edalati, S. Toh, H. Iwaoka, M. Watanabe, Z. Horita, D. Kashioka, K. Kishida and H. Inui: Scr. Mater. 67 (2012) 814-817.

41) M. Kawasaki: J. Mater. Sci. 49 (2014) 18-34.

42) O. Bouaziz, Y. Bréchet and J.D. Embury: Adv. Eng. Mater. 10 (2008) 24-36.

43) K. Lu: Science 345 (2014) 1455-1456

44) X.L. Wu, P. Jiang, L. Chen, F. Yuan and Y.T. Zhu: Proc. Natl. Acad. Sci. USA 111 (2014) 7197-7201.

45) X.L. Wu, P. Jiang, L. Chen, J.F. Zhang, F.P. Yuan and Y.T. Zhu: Mater Res. Lett. 2 (2014) 185-191.

46) X. Wu and Y. Zhu: Mater. Res. Lett. 5 (2017) 527-532.

47) Z. Fu, B.E. MacDonald, Z. Li, Z. Jiang, W. Chen, Y. Zhou and E.J. Lavernia: Mater. Res. Lett. 6 (2018) 634-640.

48) J.F. Archard: J. Appl. Phys. 24 (1953) 981-988. 